\title{
RESEÑA
}

\section{China, el ascenso del dragón, Luis González}

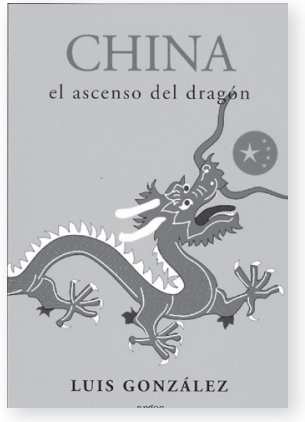

la superficie de los territorios de los cuatro países representa $26 \%$ de la super-
ficie del orbe, y su población $42 \%$ de la mundial; en los ocho años pasados, la
mitad del crecimiento económico global se ha atribuido a las contribuciones de
esos cuatro países, y en la crisis financiera que se extiende por todo el mundo,
ellos han demostrado una extraordinaria fuerza de resistencia. la superficie de los territorios de los cuatro países representa $26 \%$ de la super-
ficie del orbe, y su población $42 \%$ de la mundial; en los ocho años pasados, la
mitad del crecimiento económico global se ha atribuido a las contribuciones de
esos cuatro países, y en la crisis financiera que se extiende por todo el mundo,
ellos han demostrado una extraordinaria fuerza de resistencia. la superficie de los territorios de los cuatro países representa $26 \%$ de la super-
ficie del orbe, y su población $42 \%$ de la mundial; en los ocho años pasados, la
mitad del crecimiento económico global se ha atribuido a las contribuciones de
esos cuatro países, y en la crisis financiera que se extiende por todo el mundo,
ellos han demostrado una extraordinaria fuerza de resistencia. la superficie de los territorios de los cuatro países representa $26 \%$ de la super-
ficie del orbe, y su población $42 \%$ de la mundial; en los ocho años pasados, la
mitad del crecimiento económico global se ha atribuido a las contribuciones de
esos cuatro países, y en la crisis financiera que se extiende por todo el mundo,
ellos han demostrado una extraordinaria fuerza de resistencia. ellos han demostrado una extraordinaria fuerza de resistencia.

Hace una década, Jim O’Neill acuñó el acrónimo BRIC iniciales de Brasil, Rusia, India y China - en referencia a un grupo de países a los que auguró una proporción cada vez mayor del crecimiento mundial. A diez años de distancia, la realidad ha superado todas sus expectativas. ${ }^{2}$

De ahí que, para este economista jefe del grupo Goldman Sachs, ${ }^{3}$ estos cuatro países constituyan las "cuatro grandes economías emergentes que podrían ser capaces de dominar el mundo en el futuro". Entre los datos duros que respaldan esta aseveración, destacan los que siguen:

1. Profesor-investigador del Departamento de Estudios Políticos del Centro Universitario de Ciencias Sociales y Humanidades, Universidad de Guadalajara. ORCID http:// orcid.org/0000-0002-4078-9451

2. Isabel Lafont, "El cumpleaños de los BRIC"; en El País.com. Disponible en: http://www.elpais. com/articulo/economia/global/cumpleanos/BRIC/elpepueconeg/20061203elpnegeco_2/ Tes. Fecha de consulta 3 de diciembre de 2006.

3. Entrevista a Jim O'Neill, creador del concepto de grupo BRIC, en Spanish.CHINA.ORG.CN. Disponible en; http://spanish.china.org.cn/specials/txt/2010-04/15/content_19823421. htm. 
En especial, se señala el vigor y dinamismo de la República Popular China que, paulatinamente, comienza a tomar en cuenta el estímulo de su demanda interna, y que encabeza la calificación otorgada por la firma Goldman Sachs, puesto que se estima que en menos de dos décadas el volumen global de su economía alcanzará a la estadounidense. Se trata de un gigante que, de acuerdo con el censo de noviembre de 2010, cuenta con una población de 1,339 millones de habitantes y que presenta elevadas tasas anuales de crecimiento económico sostenido, a partir de planes quinquenales, que lo convierten en la segunda economía del mundo.

Esto significa que el Estado continúa desempeñando el rol de regulador directo de la economía, mediante la dirección del Comité Central del Partido Comunista que, cada cinco años, celebra un congreso que decide sobre la conducción política, y que en 2012 prevé un recambio generacional de los líderes, o lo que es lo mismo, el tránsito de la tercera a la cuarta generación de liderazgo.

La obra de Luis González, el sinólogo más reconocido de Centroamérica y el Caribe, da cuenta del auge de China, situación que interpreta como "el ascenso del dragón", ya que para entender este fenómeno se debe tener en cuenta la dimensión cultural de una civilización milenaria que, no obstante su régimen político, conserva y cultiva sus tradiciones. Precisamente, para los chinos, el dragón es el símbolo de la más fausta, consagrada, inteligente y protectora de las criaturas del planeta.

El libro está integrado por diez capítulos que incluyen información básica sobre el devenir histórico, la geografía, la cultura, el arte, la literatura, el gobierno, la política, la economía, el comercio y los negocios y, fundamentalmente, una discusión sobre su política exterior, caracterizada por lo que Joseph S. Nye denomina soft power en el concierto de las naciones. El autor sostiene que a eso debe China, en gran parte, el éxito de sus relaciones internacionales y comerciales, que le han permitido incursionar, entre otras regiones, en África y Latinoamérica.

Sin embargo, este gigante intenta desarrollar — paralelamente — su poder naval, al pretender transformar su armada, denominada People's Liberation Army Navy (PLAN, por sus siglas en inglés) en una Blue Water Navy, capaz de 
proyectarse al Pacífico occidental. ${ }^{4}$ El empujón inicial de este salto cualitativo al que aspira China es el aprestamiento del portaaviones "Shi Lang" —llamado así en honor al almirante del siglo XviI que conquistó Taiwán-, que recientemente se hizo a la mar. ${ }^{5}$ Tal vez se trate de un escenario futuro en el que China continental estaría dispuesta a combinar soft power y hard power, dependiendo del caso o situación que se presente y afecte sus intereses vitales.

Finalmente, este internacionalista dominicano y profesor de la Universidad del Caribe, asegura que un gran poder conduce a una gran responsabilidad, en un marco signado por liderazgos emergentes — como los BRIC y, en particular, la República Popular China-, que reclaman espacios en el (des) orden mundial. En síntesis, se trata de una lectura obligada para todo aquel estudioso que quiera informarse seriamente sobre los contenidos y alcances del ascenso irreversible de China continental. my

4. Fuerza naval expedicionaria de largo alcance, de conformidad con la Royal Navy. Véase: British Maritime Doctrine, BR 1806, by Command of the Defense Council, Her Majesty's Stationery Office, Londres, 2004, $3^{\text {a }}$ edición.

5. Véase por ejemplo; "El portaaviones chino "Shi Lang" se hizo a la mar". Disponible en: http://ellinceanalista.wordpress.com/2011/08/15/el-portaaviones-chino-shi-lang-sehizo-a-la-mar/. También: El Cronista Comercial, 27 de julio de 2011, "China muestra su creciente poder militar con su primer portaaviones". Disponible en: http://190.2.45.91/ contenidos/2011/04/27/noticia_0018.html. Para una apreciación estratégica, se recomienda consultar: Philip Walker, "Beijing's Blue-Water Navy. Is China building an empire on the sea?", en Foreign Policy, 3 de junio de 2011. Disponible en: http://www.foreignpolicy.com/ articles/2011/06/03/Beijings_blue_water_navy. 